\title{
Leptospirose humana: situação epidemiológica em Belém - Pará
}

\author{
Human leptospirose: epidemiological situation in Belém - Pará \\ Leptospirosis humana: situación epidemiológica en Belém - Pará
}

Luan Daniel Silva Ferreira ${ }^{1 *}$, Laura Cristina Correa Costa1 ${ }^{1}$, Bruno Pantoja Gadelha1, Erlane Paiva Russo ${ }^{1}$, Priscila Cerdeira Coelho de Sousa ${ }^{1}$, Analice Ramos Fernandes ${ }^{1}$, Fabiolla da Silva dos Santos ${ }^{1}$, Rosiane Paiva Russo ${ }^{2}$, Douglas Silva dos Santos ${ }^{3}$, Antonio Carlos Monteiro Filho ${ }^{4}$.

\section{RESUMO}

Objetivo: Fornecer informações sobre a situação epidemiológica da leptospirose na cidade de Belém - Pará, entre o período de 2010 a 2019. Métodos: Foi realizado um estudo descritivo-analítico, de base populacional, dos casos notificados e confirmados de leptospirose no Município de Belém. Os dados utilizados foram coletados na base de dados do Sistema de Informação de Agravos de Notificação (SINANNET) pertencente ao DataSUS. Foi analisada a incidência dos casos de leptospirose ao decorrer dos anos. Resultados: Foram confirmados 644 casos de leptospirose. O maior volume de casos foi registrado nos meses de janeiro a maio, coincidindo com a época de maior precipitação pluviométrica e marés altas. O maior percentual de infecção, ocorreu em indivíduos do sexo masculino, com 80,59\%. Em área urbana um total de $76,08 \%$ casos. Dos casos confirmados por evolução, $76,40 \%$ foram curados, $16 \%$ tiveram óbito. Verificou-se um aumento na incidência, com o coeficiente de correlação $\left(R^{2}\right)$ igual a 0,5574 . Conclusão: A ocorrência dos casos está associada aos períodos de altos índices de pluviosidades, alagamentos e a falta de saneamento básico na capital, condições que são favoráveis para a bactéria se disseminar.

Palavras-chave: Incidência, Infecção, Casos notificados.

\begin{abstract}
Objective: To provide information on the epidemiological situation of leptospirosis in the city of Belém - Pará, from 2010 to 2019. Methods: A descriptive-analytical population-based study of notified and confirmed cases of leptospirosis in the city of Belém was carried out. The data used were collected from the Information System for Notifiable Diseases (SINANNET) belonging to DataSUS. The incidence of leptospirosis cases over the years was analyzed. Results: 644 cases of leptospirosis were confirmed. The greatest volume of cases was registered in the months of January to May, coinciding with the period of greater rainfall and high tides. The highest percentage of infection occurred in males, with $80.59 \%$. In urban areas a total of $76.08 \%$ cases. Of the cases confirmed by evolution, $76.40 \%$ were cured, $16 \%$ died. There was an increase in incidence, with the correlation coefficient (R2) equal to 0.5574 . Conclusion: The occurrence of cases is associated with periods of high rainfall, flooding and lack of basic sanitation in the capital, conditions that are favorable for the bacteria to spread.
\end{abstract}

Keywords: Incidence, Infection, Reported cases.

\section{RESUMEN}

Objetivo: Proporcionar información sobre la situación epidemiológica de la leptospirosis en la ciudad de Belém - Pará, de 2010 a 2019. Métodos: Se realizó un estudio poblacional descriptivo-analítico de casos notificados y confirmados de leptospirosis en la ciudad de Belém. Los datos utilizados fueron recolectados del Sistema de Información de Enfermedades Notificables (SINANNET) perteneciente a DataSUS. Se analizó la incidencia de casos de leptospirosis a lo largo de los años. Resultados: se confirmaron 644 casos de leptospirosis. El mayor volumen de casos se registró en los meses de enero a mayo, coincidiendo con el

\footnotetext{
${ }^{1}$ Escola Superior da Amazônia, Belém - PA. *E-mail: luan.ferreirabio@gmail.com

2 Faculdades Integradas Norte do Paraná (UNOPAR), Barcarena - PA.

3 Instituto Tecnológico Vale, Belém - PA.

4 Universidade Federal Rural da Amazônia, Belém - PA.
} 
período de mayor precipitación y pleamar. El mayor porcentaje de infección se presentó en varones, con un $80,59 \%$. En las zonas urbanas un total de 76,08\% de casos. De los casos confirmados por evolución, el $76,40 \%$ se curaron, el $16 \%$ falleció. Hubo un aumento de la incidencia, con el coeficiente de correlación ( $\left.R^{2}\right)$ igual a 0,5574. Conclusión: La ocurrencia de casos se asocia con períodos de alta precipitación, inundaciones y falta de saneamiento básico en la capital, condiciones favorables para la propagación de la bacteria.

Palabras clave: Incidencia, Infección, Casos notificados.

\section{INTRODUÇÃO}

Considerada uma zoonose de relevância mundial, a leptospirose atinge animais e humanos, podendo causar infecção grave. Tanto os animais domésticos quanto os silvestres exercem o papel de reservatório. Nesse sentido, em área urbana, cães, animais de produção, bem como os roedores sinantrópicos, apresentam-se como reservatórios mais importantes, de modo que, este, é considerado o principal. Dentro da cadeia de transmissão, o homem é classificado como hospedeiro acidental e terminal (MINISTÉRIO DA SAÚDE, 2014).

A primeira vez que a doença foi descrita, data do ano de1880, no Egito (cidade de Cairo), por Larrey, entretanto, foi em 1886 que Weil descreveu minuciosamente quatro casos clínicos em humanos (JAMAS LT, et al., 2020). A Leptospira spp é uma espiroqueta, móvel, tem forma espiralada. No meio ambiente sob condições favoráveis de umidade, temperatura (de $\left.28-30^{\circ} \mathrm{C}\right)$ e pH ideal $(7,2$ a 7,4$)$, podem sobreviver por até 180 dias. As leptospiras em geral não são hospedeiro-específica, todavia, alguns sorovares demonstram afinidade por determinados hospedeiros como sorovar Canícola em cães, Icterohaemorrhagiae, para roedores, Pomona para suínos e Hardjo para bovinos (GENOVEZ ME, 2016).

O conhecimento da leptospirose vem por volta de 1800, e foi analisada por Adolf Weil, médico alemão, ao final desse mesmo século. Em meados do século XIX, Stimson observou em cortes histológicos, nomeando de Spirocheta interrogans o agente causador da infecção. Em 1915, foram comprovados, tanto na Asia como na Europa, que a doença se dá através de um microrganismo contagioso (LARA JM, et al., 2019).

Pressupõem-se que as embarcações as quais transportavam os escravos, vindos da África para o Brasil, trouxeram também ratos contaminados com Leptospira spp. Na década de 1960, na capital carioca, houveram relatos dos casos primários da doença, e foram justamente no período das grandes chuvas veraneias. Contemporaneamente, os dados mostram que a taxa média de casos é em torno de 3600 , acompanhado por 375 mortes anuais (MINISTÉRIO DA SAÚDE, 2019). Devido a sua morfologia e motilidade, as leptospiras entram no organismo, de forma ativa, por meio das mucosas e pele íntegra ou lesada (ADLER B, 2015; ELLIS WA, 2015).

Nos rins elas se deparam com o ambiente ideal, o qual fornece proteção contra o sistema imune do hospedeiro, são eliminadas pela urina e contaminam todo o ambiente, podendo também ser expelidas pelo fluido vaginal. Nesse sentido, a transmissão ocorre por contato direto, seja com a urina de animal portador, ou mesmo com água, solo e fômites (PICARDEAU M, 2013; LOUREIRO AP e LELENBAUM W, 2020).

A penetração ativa dos micro-organismos pelas mucosas, pele escarificada ou integra estão inclusas na patogenia. Subsequentemente as leptospiras multiplicam-se no espaço intersticial e nos humores orgânicos (sangue, linfa e líquor), caracterizando um quadro agudo septicêmico de leptospiremia (JAMAS LT, et al., 2020). A doença pode ser adquirida, portanto, pelo contato com a urina, água ou solo contaminados com a bactéria e adentram no organismo, se disseminam pela corrente sanguínea, atingindo órgãos específicos como fígado, pulmões e rins, onde podem sobreviver por meses (FERNANDES LG, et al., 2016).

O conhecimento sobre a patogenicidade da leptospirose ainda é raso, sabe-se que através da urina de certos animais infectados pela bactéria Leptospira ssp, pode-se contrair a doença, ocorrendo de modo extemporâneo, de modo histórico era colocada como uma doença do meio rural, e na atualidade acarreta frequentemente as populações urbanas (HOTEZ PJ, 2017). 
No homem ocorre que, casualmente abriga a bactéria dando continuidade para o ciclo de propagação da doença. Desse modo, a causa da infecção é decorrente do contato direto ou mediato, com a urina de mamíferos contaminados. O microrganismo adentra no hospedeiro por meio de áreas lesionada ou não, das mucosas e da pele. Existe uma correlação positiva entre ambientes inundados e a contaminação por essa bactéria. Portanto, a leptospirose se faz presente o ano todo, e maioria das incidências da doença são nos meses considerados chuvosos (MINISTÉRIO DA SAÚDE, 2014).

Os sintomas da leptospirose são comumente confundidos com sintomas de outras doenças e infecções, caracterizando um mimetismo: na sua forma mais moderada é facilmente confundida com outras doenças que possuem sintomas iguais. Esse fator tem cobrado um avanço nas atividades de monitoramento e diagnóstico, visando expandir as formas de identificação dos casos. Para tal, essa bagunça no diagnóstico vem chamando o foco dos pesquisadores, pois as infecções causadas por patógenos destinos, mostram sintomas parecidos, mas possuem tratamentos segregados, levando a morte, caso seja aplicado um tratamento errado (PRIYA SP, et al., 2017).

No território brasileiro, a leptospirose é atrelada a sazonalidade, onde há aumento significativo dos casos, em períodos com maior pluviosidade. Outros fatores que ajudam a elevar o número de ocorrência é a maior densidade demográfica, pessoas em situações precárias, de moradia, de higiene, acrescido da invasão eminente por roedores das mais variadas espécies, em particular nos centros das cidades. Isso faz com que, - Brasil se coloque entre os 20 países que são endêmicos para leptospirose. O Sudeste abrange a área de maior registro de casos e, no período de 2006 a 2011, notificou 36,8\% deles. A Região Norte retém 10,6\% dos casos e, nela o Estado do Pará lidera em números absolutos (MINISTÉRIO DA SAÚDE, 2016).

São localizadas no município de Belém, grandes áreas que propiciam enormes riscos e facilitam o surgimento da leptospirose. O principal causador dessa situação é a ocupação desordenada e as nuances advindas dos terrenos bagunçados. Desse modo, ainda há uma cera falta de ferramentas que objetivem colocar limites aos locais de risco aumentado (LIMA RJS, et al., 2012).

O clima em Belém é quente e úmido com precipitação média anual de aproximadamente $2.834 \mathrm{~mm}$, no entanto, nas últimas décadas, devido a ocorrência de eventos climáticos, como exemplos o El Niño e o La Niña, tais características têm sofrido alterações. Acidentes geográficos como o Rio Guamá, as Bacias do Rio Guajará e do Marajó são importantes na sua conformação. Em fevereiro, a temperatura média na cidade é de $25^{\circ} \mathrm{C}$ e em novembro é de $26^{\circ} \mathrm{C}$, com ausência de estação fria, o que se apresenta como condições ideais para que o patógeno, quando suspenso em meio hídrico, continue infectante por até seis meses, em média (BERNARDI I, 2012).

Com o processo de urbanização desorganizada ou desmatamento em regiões de margem, ocorre a destruição de áreas ribeirinhas, o que altera o curso natural e o fluxo dos rios. Esse fator age como um facilitador, contribuindo para a maior extensão das inundações e, consequentemente, expondo um maior número de pessoas à doença (SANTOS L, et al., 2012). As baixadas de Belém, por apresentarem grandes extensões com cotas altimétricas de 4 metros, sofrem influência das marés altas e, por esse motivo, apresentam dificuldade para o escoamento das águas pluviais (GONÇALVES NV, et al., 2016).

Sob essa perspectiva, o presente estudo teve como objetivo fornecer informações de grande relevância sobre a situação epidemiológica da leptospirose na cidade de Belém - Pará, no período de 2010 a 2019 , podendo assim, auxiliar nas tomadas de decisões quanto as medidas de controle da doença.

\section{MÉTODOS}

Foi realizado um estudo descritivo-analítico, de base populacional e sem coleta de material biológico, de acordo com as normas de pesquisa do Conselho Nacional de Saúde, dos casos notificados e confirmados de leptospirose no Município de Belém, no período de janeiro de 2010 a dezembro de 2019.

Os dados utilizados foram coletados na base de dados do Sistema de Informação de Agravos de Notificação (SINANNET) pertencente ao DataSUS. Após a coleta dos dados, foram feitos agrupamento em categorias dos mesmos, por conseguinte, a elaboração de gráficos utilizando o Software R (versão 4.1.1). 
Com base no objetivo de descrever a situação epidemiológico da doença, foram selecionadas no banco de dados do DataSUS, as seguintes variáveis: i) Série histórica no período de 2010 a 2019; ii) Frequência por sexo e faixa etária; iii) Frequência por característica e local de infecção; (iv) Frequência por característica e informação ambiental; v) Critérios de confirmação para o diagnóstico da doença e evolução dos casos.

Por fim, foi analisada a incidência dos casos de leptospirose ao decorrer dos anos estudados, com ajuda de um gráfico de dispersão e linha de tendencia, com um desvio padrão de $0,5 \%$.

\section{RESULTADOS}

Foram confirmados, no Município de Belém, 644 casos de leptospirose, onde apenas 524 residiam na cidade, representando 50,11\% (644/1285) do total de casos do Estado do Pará entre 2010 e 2019. O maior volume de casos foi registrado nos meses de janeiro a maio, coincidindo com a época de maior precipitação pluviométrica e marés altas.

Picos iguais ou acima de 19 casos foram observados em 8 períodos da série histórica: (I) entre fevereiro e março de 2011 ( $n=44)$; e (II) entre março e abril de 2013 ( $n=42$. (III) entre fevereiro a maio de $2014(n=$ 94). (IV) entre abril e maio de $2015(n=41)$. (V) março de $2016(n=24)$. (VI) entre fevereiro e maio de 2017 (73). (VII) entre fevereiro e março de $2018(n=54)$. (VII) e por último, entre março e maio de $2019(n=69)$. $\mathrm{O}$ ano que apresentou maiores casos foi o de 2014 com 146 e o menor foi de 2010 com 98 casos confirmados (Figura 1).

Figura 1 - Casos confirmados por Ano/Mês de Leptospirose me Belém, 2010 a 2019.

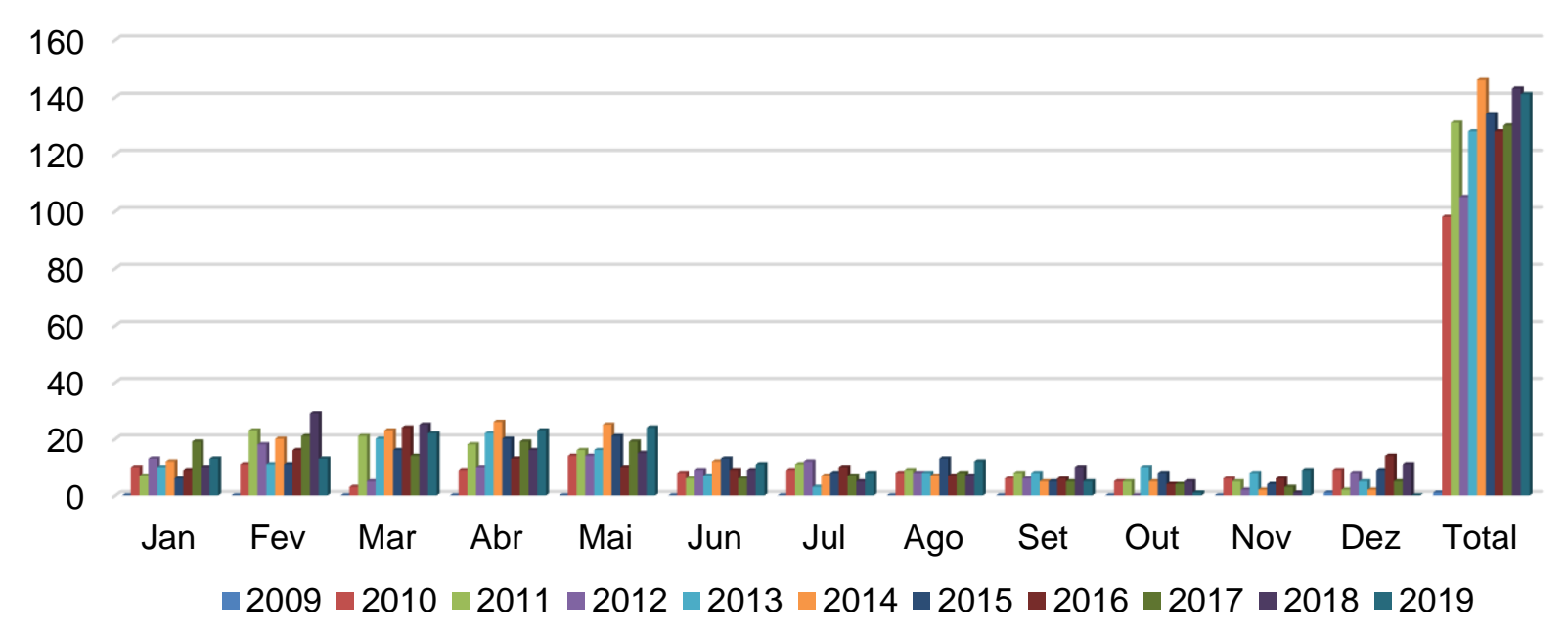

Fonte: Ferreira LDS, et al., 2021.; Dados extraídos do Sistema de Informação de Agravos de Notificação, 2021.

A época de cheias ou marés altas começa nos últimos dois meses do ano, e se estende até metade do ano. A leptospirose pode ser vinculada com os alagamentos e inundações, sendo causada por uma bactéria, contagio-infecciosa, cujo sintoma principal é a febre alta, e surge frequentemente nas áreas de clima tropicais (LONDE LR, et al., 2016).

Alguns poucos trabalhos feitos nacionalmente, revelou que as realidades socioeconômicas de periferias urbanas e centros inflados, é um elemento chave que eleva o aparecimento de surtos da doença. Portanto, regiões frágeis e de fácil surgimento da doença são as que possuem menor investidura em higiene e esgoto, conjuntamente a um mal plano urbanístico (MINERVINO AC e DUARTE EC, 2016).

Nos primeiros semestres de estudo houve a ocorrência de maior notificação dos casos, o que pode estar associada ao acontecimento de fenômenos climáticos como o El Niño, o qual possui como principal característica a incidência de alta pluviosidade. Nesse sentido, esta, ligada às baixas cotas altimétricas das áreas próximas aos canais a céu aberto na área de estudo, acarretaram quadros de enchentes, as quais são fatores de risco de propagação da doença (SAMPAIO GP, et al., 2011). 
O maior percentual de infecção, ao longo de toda a série de estudo, ocorreu em indivíduos do sexo masculino, com 80,59\% (519/644), sendo a razão entre os sexos de 4:1 (Figura 2).

Figura 2 - Gráfico da distribuição percentual dos casos de leptospirose por sexo.

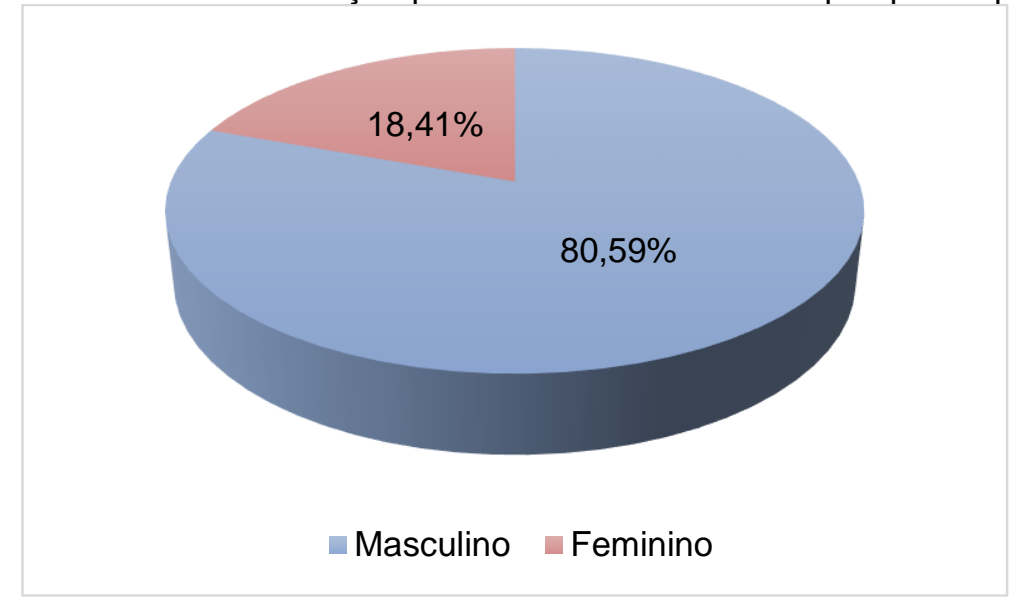

Fonte: Ferreira LDS, et al., 2021.; Dados extraídos do Sistema de Informação de Agravos de Notificação, 2021.

Os seres humanos são frequentemente acometidos pela doença, na maioria das vezes a doença e caracterizada por ser grave, levando os indivíduos a internação. Não existe uma comprovação de predisposição por gênero, mas pode-se relacionar com a atividade laborativa, uma vez que indivíduos do sexo masculino estão mais expostos a situações ou práticas que facilitem o contato com fontes de infecção.

A deficiência em infraestrutura sanitária, amontoados urbanos e a condição social e econômica vulnerável, níveis insignificantes de educação escolar, ocupação profissional, pragas de roedores e concentração de lixos, acabam ajudando o surgimento de surtos (SCHNEIDER MC, et al., 2015).

Aproximadamente $43,47 \%$ (280/644) dos casos notificados foram na faixa etária de 20 a 39 anos. Os casos com menores de 9 anos compreenderam 1,55\% (10/644). Foram registrados 39 casos em pessoas acima de 65 anos de idade, sendo $6,05 \%$ do total. Com relação à idade, observa-se uma incidência geralmente mais alta de leptospirose entre pessoas de 20 a 40 anos de idade, com uma taxa muito mais baixa nos maiores de 60 anos, possivelmente por este grupo etário já ter sofrido alguns episódios subclínicos ou inaparentes da enfermidade.

Por outro lado, 76,08\% (490/644) do total de casos confirmando foram caracterizados em área urbana, $5,2 \%(34 / 644)$ em área rural e 2,2\% (14/644) em área periurbana (Figura 3).

Figura 3 - Porcentagens casos por informação de localização da área.

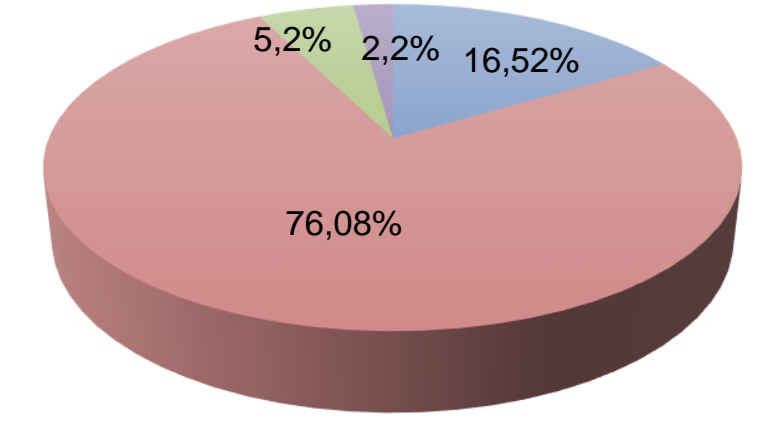

$\square \operatorname{lgn} /$ Branco Urbana $\square$ Rural $\square$ Periurbana

Fonte: Ferreira LDS, et al., 2021.; Dados extraídos do Sistema de Informação de Agravos de Notificação, 2021. 
A disseminação da doença está associada ao local em que as pessoas residem ou trabalham, sendo assim, áreas sujeitas a alagamento, próximas a esgotos, lixo acumulado e também com a presença de roedores, são consideradas como um indicativo de fator de risco.

A falta de infraestrutura básica, inchaço populacional nos centros urbanos, fragilidade socioeconômica, menor instrução educacional, trabalho, presença exacerbada de ratos e concentração de lixo nas ruas, aumentam de forma abrupta para o surgimento de surtos (SCHNEIDER MC, et al., 2015).

Quando analisados os casos em relação as características, localização e informações ambientais, temos $47,67 \%$ (307/644) sendo em localização domiciliar (80/644) em local de trabalho, $28,41 \%$ classificado como outros e $12,42 \%$ em local de trabalho (Figura 4).

Figura 4 - Porcentagem de casos em relação a característica da área.

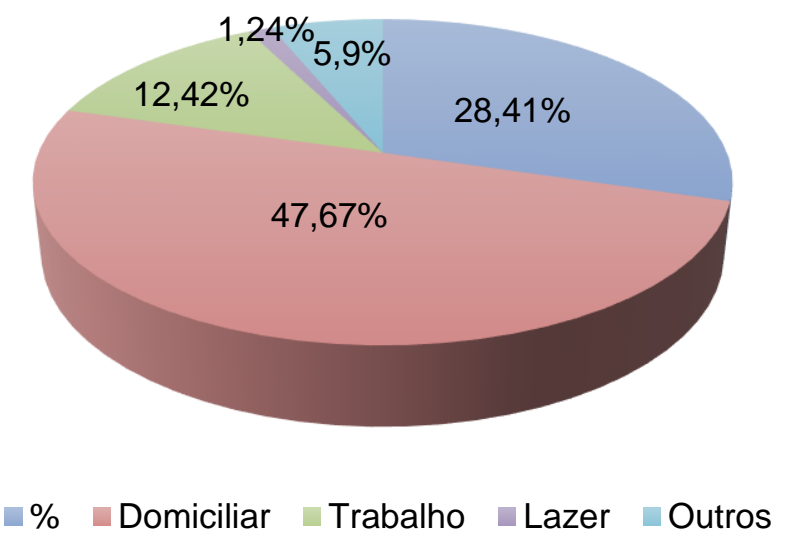

Fonte: Ferreira LDS, et al., 2021.; Dados extraídos do Sistema de Informação de Agravos de Notificação, 2021.

Conforme Gutierrez JD (2021), é comum que nos trabalhos realizados, a maior incidência de casos por área/local, sejam nos centros urbanos ou/e ambiente domiciliar, e esses dados são corroborados com diversos outros, no mesmo período anual e em anos antecedentes, no Brasil. Outrossim, a contaminação dos trabalhadores está associada ao contato direto com saneamento e manuseio de materiais, como águas, bueiros, esgotos, coletas de lixo, uma vez que estes podem estar infectados por roedores, apresentando assim, alto risco de transmissão da doença pelo micro-organismo.

Cerca de metade dos casos de leptospirose foi por infecção no próprio domicílio. Nos períodos de inundações, a água invade as casas próximas aos rios e córregos, expondo os moradores ao risco do contato com a água contaminada pela urina dos roedores. Estes autores relacionaram a doença à vulnerabilidade socioeconômica em conjunto com altos índices pluviométricos (GONÇALVES NV, et al., 2016).

A Leptospirose é comumente diagnosticada como "virose", "síndrome gripal" ou outras doenças que se propagam no mesmo período, como a influenza e a dengue. Nesse sentido, ressalta-se a presença de alguns sinais e sintomas que podem contribuir na diferenciação das fases precoces da leptospirose de outras causas de doenças febris agudas. Desse modo, obter um histórico sobre exposição epidemiológica de risco dos casos suspeitos é de extrema relevância, a fim de contribuir para o diagnóstico clínico da doença (BRASIL, 2014). Para o critério de confirmação foi 357 para clínico-laboratorial, 278 para clínico-epidemiológico e 9 foram ignorados ou em branco.

Atualmente, o método padrão de diagnóstico para leptospirose é baseado em testes indiretos como a sorologia, principalmente a aglutinação microscópica (MAT) e métodos diretos, como cultura bacteriológica e reação em cadeia de polimerase (PCR) (GENOVEZ ME, 2016). Nesses casos, pacientes infectados apresentam títulos de IgM e lgG que são detectados pela MAT ou ELISA. Para a detecção do agravo, o diagnóstico pode ser laboratorial ou clínico-epidemiológico. Existe uma escolha preferencial pelo diagnóstico clínico-laboratorial, pois esse expõe informações mais minuciosas para os médicos (MARTINS MHM E SPINK MJP, 2020). 
O fato de a infecção mostrar sinais parecidos com outras, tem chamado a atenção dos pesquisadores do ramo. A preocupação é que, uma medicamentação impropria pode aumentar a probabilidade de morte dos pacientes (PRIYA SP, et al., 2017).

Quando observado os casos confirmados por evolução, 76,40\% (492/644) foram curados, $16 \%$ (103/644) tiveram óbito pelo agravo notificado, 0,6\% tiveram óbito por outra causa e 7\% (45/644) foi ignorado ou em branco.

No início da infecção por Leptospira ssp. os sintomas podem ser confundidos com os de várias outras infecções. Em consequência da ação errônea para identificação da infecção e aplicação do devido tratamento de maneira retardada, há grande chance da evolução do quadro, e consequentemente, um mal prognóstico (RODRIGUES CM, 2016).

Entre os anos de 1980 a 2000, houve uma taxa de letalidade de $12,5 \%$ em todo país. Alguns trabalhos realizados em Belém - PA, mostraram que no período de tempo de 2005 a 2012, a taxa de letalidade foi em torno de 17\%. (LIMA RJS, et al., 2012).

A baixa notificação pode estar associada ao fato de doença, muitas vezes, ser confundida com viroses tropicais, o que dificulta o acesso a um diagnóstico mais precoce e preciso ainda na atenção primária devido a fase aguda ser de difícil percepção clínica. Nesse sentido, determinar a real incidência e a efetiva carga global é fundamental conhecer a magnitude da leptospirose (HARTSKEERL RA, et al., 2011).

Dessa forma, deve-se salientar que a notificação, em muitas vezes, somente é feita para os casos mais graves da doença, trazendo algumas consequências relevantes como o registro abaixo do real das mortes por leptospirose e uma alta nas taxas de letalidade. Portanto, grande parte dos casos notificados no Brasil, advêm das anotações dos hospitais, limitando-se aos indivíduos que apresentam a forma evoluída ou grave da doença (SEGURADO AC, et al., 2016).

Ao observar a incidência dos casos ao decorrer dos anos, houve uma variação de 33 casos nos de 2010 para 2011, sendo classificada como a maior incidência. Já nos de 2016 a 2019, houveram variação de 2 casos por ano, considerado assim, os anos com menor incidência de casos. Na avaliação da incidência da série temporal, verificou um aumento na incidência, com o coeficiente de correlação $\left(R^{2}\right)$ igual a 0,5574 (Figura 5).

Figura 5 - Incidência dos casos de leptospirose ao decorrer da série temporal em estudo.

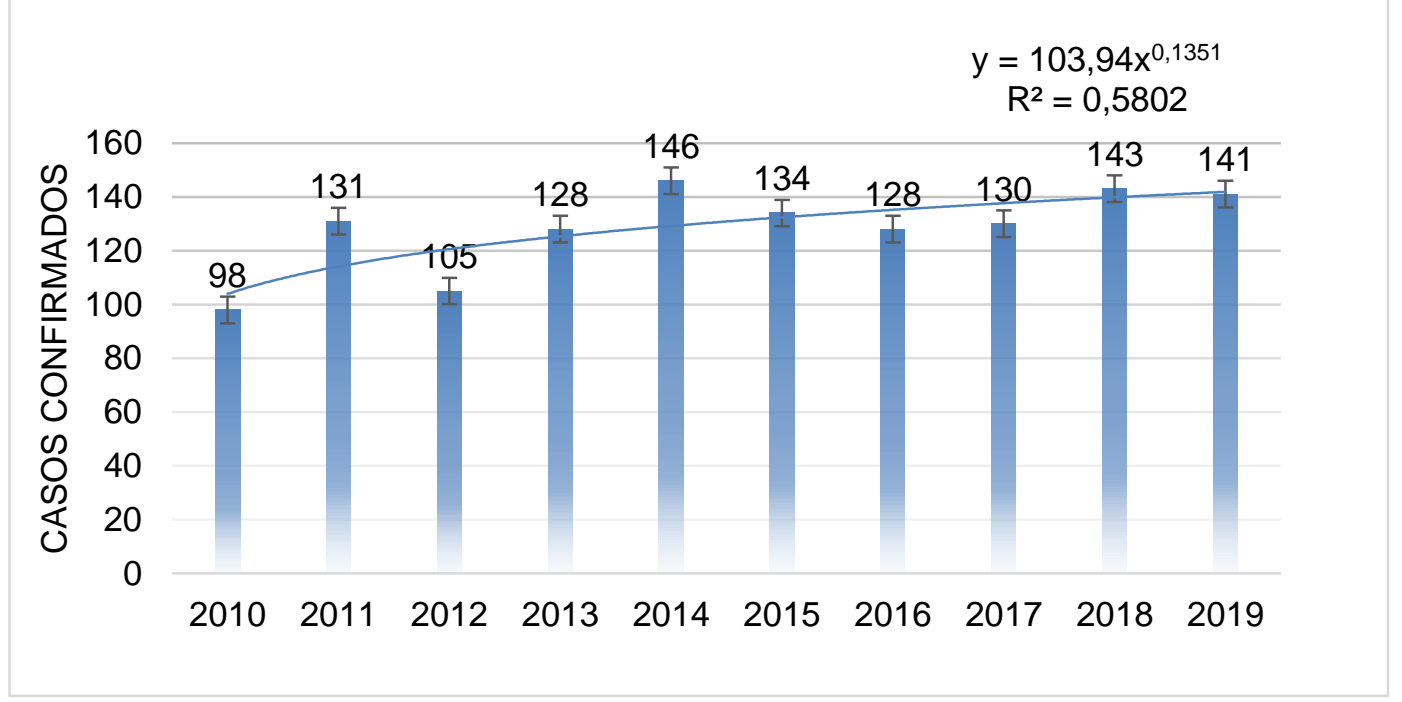

Fonte: Ferreira LDS, et al., 2021.

Relaciona-se os surtos de leptospirose no Brasil à ocorrência de inundações em alguns municípios brasileiros. Questões relacionadas a monitoramento conjunto entre os casos de leptospirose e a ocorrência climática e concluíram que os dados de inundação também podem ser úteis para a análise de surtos tanto quanto os dados de precipitações (LONDE LR, et al., 2016). 
De acordo com o Sistema de Informação de Agravos de Notificação (SINAN) o Brasil teve 3.358 casos notificados de leptospirose em 2019. Portanto, é de extrema importância essa inserção de dados dos índices de leptospirose nas plataformas, para compreender se a mesma deve ser considerada uma doença negligenciada (LACERDA FB, et al., 2021).

Os centros urbanos e as metrópoles, possuem características únicas, tal quais as condições desumanas para moradia, higiene, e principalmente, a falta de estrutura para escoamento do esgoto. Essas condições, são favoráveis para o crescimento populacional dos roedores, contribuindo para o aumento da leptospirose nessas regiões. A quantidade aumentada de ratos tem relação direta e proporcional com os locais e as condições de deficiência sanitária, de água limpa e usual, de recolhimento de lixo e socioeconômicas (PAPINE S, 2012).

Atualmente a leptospirose é uma doença de áreas urbanas, principalmente em locais com crescimento desordenado e com precariedade de saneamento básico (CHAIBLICH JV, et al. 2017).

\section{CONCLUSÃO}

A ocorrência dos casos está associada aos períodos de altos índices de pluviosidades, alagamentos e a falta de saneamento básico na capital, condições que são favoráveis para a bactéria se disseminar. 0 diagnóstico clínico-epidemiológico, apresenta dificuldade para identificar a Leptospira ssp, pois existe uma gama enorme de sintomas, que por muitas vezes mimetizam outras infecções. Diante isso, o diagnóstico laboratorial é indispensável para identificar a leptospirose. Outro ponto relevante, foi referente aos casos diagnosticados por evolução da doença, onde se observou que a maioria dos casos confirmados foram curados. No município de Belém, a leptospirose é uma doença que afeta grande parte da população que vive na zona urbana. O estudo em si, possibilitou verificar que na série temporal analisada, obteve-se importantes informações epidemiológica da leptospirose.

\section{AGRADECIMENTOS E FINANCIAMENTO}

Agradecimentos a Escola Superior da Amazônia (ESAMAZ), pelo suporte disponibilizado na elaboração desse estudo.

\section{REFERÊNCIAS}

1. ADLER B. History of leptospirosis and leptospira. Current Topics in Microbiology and Immunology. 2015; 387(1): 79-84.

2. BERNARDI I. Leptospirose e saneamento básico. Monografia (Especialização em Saúde Pública) -Centro de Ciências da Saúde. Universidade Federal de Santa Catarina, Florianópolis, 2012; 18 p.

3. CHAIBLICH JV, et al. Estudo espacial de riscos à leptospirose no município do Rio de Janeiro (RJ). Saúde debate, 2017; 41: 225-240.

4. ELLIS WA. Animal leptospirosis. Current Topics in Microbiology and Immunology. Tokyo, 2015; 387(1): 99-137.

5. FERNANDES LG, et al. Leptospira spp: novel insights into host-pathogen interactions. Vet Immunol Immunopathol. 2016; 176: 50-57.

6. GENOVEZ ME. Leptospirose em animais de produção. In: MEGID J, et al. Doenças infecciosas em animais de produção e de companhia. $1^{\text {a }}$ ed. Rio de Janeiro: Roca, 2016; 378-87p.

7. GONÇALVES NV, et al. Distribuição espaço-temporal da leptospirose e fatores de risco em Belém, Pará. Brasil. Ciência e Saúde Coletiva, 2016; 3947-3955.

8. GUTIERREZ JD. Effects of meteorological factors on human leptospirosis in Colombia. Int J Biometeorol. 2021; 65(2): 257-263.

9. HARTSKEERL RA, et al. Microbiologia Clínica e Infecção. 2011; 17(4): 494-501.

10. HOTEZ PJ. Global urbanization and the neglected tropical diseases. PLoS Negl Trop Dis, 2017; 11(2): e0005308.

11. JAMAS LT, et al. Leptospirose bovina. vet. e Zootec. 2020; 27: 001-019.

12. LACERDA FB, et al. Fatores determinantes na caracterização da leptospirose como doença negligenciada: revisão integrativa. Revista Eletrônica Acervo Científico, 2021; 19: e6256.

13. LARA JM, et al. Leptospirose no município de Campinas, São Paulo, Brasil: 2007 a 2014. Rev Bras Epidemiol, 2019; 22: 2007-14. 
14. LIMA RJS, et al. Análise da distribuição espaço-temporal da leptospirose humana em Belém, Estado do Pará, Brasil. Rev Pan-Amaz Saude, 2012; 33-40.

15. LONDE LR, et al. Flood-related leptospirosis outbreaks in Brazil: perspectives for a joint monitoring by health services and disaster monitoring centers. Natural Hazards Review, 2016; 84(2): 1419-1435.

16. LOUREIRO AP, LILENBAUM W. Genital bovine leptospirosis: a new look for an old disease. Theriogenology, 2020; 141(1): 41-47.

17. MARTINS MHM, SPINK MJP. A leptospirose humana como doença duplamente negligenciada no Brasil. Ciênc. saúde coletiva, 2020; 25(3): 1-14.

18. MINERVINO AC, DUARTE EC. Danos materiais causados à Saúde Pública e à sociedade decorrentes de inundações e enxurradas no Brasil, 2010-2014: dados originados dos sistemas de informação global e nacional. Ciência \& Saúde Coletiva, 2016; 21(1): 685-694.

19. MINISTÉRIO DA SAÚDE. Guia de Vigilância em Saúde. 2019. Disponível em: https://portalarquivos2.saude.gov.br/images/pdf/2019/junho/25/guia-vigilancia-saude-volume-unico-3ed.pdf. Acesso em: 28 de outubro de 2021.

20. MINISTÉRIO DA SAÚDE. Secretaria de Vigilância em Saúde. Coordenação-Geral de Desenvolvimento da Epidemiologia em Serviços. Guia de Vigilância em Saúde. 2016. Disponível em: https://bvsms.saude.gov.br/bvs/publicacoes/guia_vigilancia_saude_3ed.pdf. Acesso em: 29 de outubro de 2021.

21. MINISTÉRIO DA SAÚDE. Secretaria de Vigilância em Saúde. Departamento de Vigilância das Doenças Transmissíveis. Leptospirose: diagnóstico e manejo clínico. 2014 . Disponível em: https://bvsms.saude.gov.br/bvs/publicacoes/leptospirose-diagnostico-manejo-clinico2.pdf. Acesso: 30 de outubro de 2021.

22. MINISTÉRIO DA SAÚDE. Resolução nำ 466 de 12 de dezembro de 2012. Dispõe sobre diretrizes e normas regulamentadoras de pesquisa envolvendo seres humanos e atualiza a resolução 196. 2013. Disponível em: https://conselho.saude.gov.br/resolucoes/2012/Reso466.pdf. Acesso em: 25 de outubro de 2021.

23. PAPINE S. Vigilância em Saúde Ambiental: uma nova área da ecologia. São Paulo: Atheneu, $2012 ; 2$.

24. PICARDEAU M. Diagnosis and epidemiology of leptospirosis. Médicine et Maladies Infectieuses, Paris, 2013; 43(1): 1-9.

25. PRIYA SP, et al. Leptospirosis: molecular trial path and immunopathogenesis correlated with dengue, malaria and mimetic hemorrhagic infections. Acta Trop, 2017; 176(1):206-223.

26. RODRIGUES CM. O círculo vicioso da leptospirose: ampliando o conceito de negligência em saúde no Brasil. Rio de Janeiro: Fundação Oswaldo Cruz, Instituto de Comunicação e Informação Científica e Tecnológica em Saúde; 2016; $1-80$.

27. SAMPAIO GP, et al. Descrição epidemiológica dos casos de leptospirose em hospital terciário de Rio Branco. Rev Bras Clín Med, 2011; 338-343.

28. SANTOS L, et al. Sobre risco, ameaça e vulnerabilidade à leptospirose em situações pós-alagamentos, inundações e enxurradas: reconstruindo o episódio do Vale do Itajaí (2008-2009). In: I Congresso Brasileiro sobre Desastres Naturais, Anais, Rio Claro/SP, 2012; 10.

29. SEGURADO AC, et al. Saúde nas metrópoles - Doenças infecciosas. Estudos Avançados, 2016; 30: 86.

30. SCHNEIDER MC, et al. Leptospirosis in Rio Grande do Sul, Brazil: ecosystem approach in the animal-human interface. PLoS-NTD, 2015; 12(9): 1-20. 